\title{
Hourly Analysis of Mechanical Ventilation Parameters in Critically III Adult Covid-19 Patients: Association with Mortality
}

\section{Tomás F. Fariña-González}

Hospital Clinico Universitario San Carlos

\section{Antonio Núñez-Reiz}

Hospital Clinico Universitario San Carlos

Julieta Latorre

Hospital La Paz: Hospital Universitario La Paz

\section{Maria Calle-Romero}

Hospital Clinico Universitario San Carlos

Viktor Yordanov-Zlatkov ( $\square$ viktoryz1111@hotmail.com )

Hospital Clinico Universitario San Carlos https://orcid.org/0000-0003-0038-2400

\section{Patricia Alonso-Martinez}

Hospital Clinico Universitario San Carlos

\section{Sara Domingo-Marín}

Hospital Clinico Universitario San Carlos

\section{Miguel Sánchez-García}

Hospital Clinico Universitario San Carlos

\section{Research}

Keywords: ARDS, mechanical ventilation, SARS-CoV-2, respiratory system mechanics

Posted Date: November 1st, 2021

DOl: https://doi.org/10.21203/rs.3.rs-1004801/v1

License: (c) (1) This work is licensed under a Creative Commons Attribution 4.0 International License. Read Full License 


\section{Abstract}

Objective: there exists controversy about the pathophysiology and lung mechanics of COVID-19 associated ARDS, because some report severe hypoxemia with preserved respiratory system mechanics, contrasting with "classic" ARDS. We performed a detailed hourly analysis of the characteristics and time course of lung mechanics and biochemical analysis of patients requiring invasive mechanical ventilation for COVID-19-associated ARDS, comparing survivors and non-survivors.

Methods and measurements: retrospective analysis of the data stored in the ICU information system of patients admitted in our hospital ICU that required invasive mechanical ventilation due to confirmed SARS-CoV-2 pneumonia between March 5th and April 30th, 2020. We compare respiratory system mechanics and gas exchange during the first ten days of IMV, discriminating volume and pressure controlled modes, between ICU survivors and non-survivors.

Results: 140 patients were analyzed, analyzing 11,138 respiratory mechanics recordings. Global mortality was $38.6 \%$. Multivariate analysis showed that age (OR 1,092, 95\% (Cl 1,014-1,176)), previous use of ACEI/ARBs (OR 4,612, (95\% Cl 1,19-17,84)) and need of renal replacement therapies (OR 10,15, (95\% Cl $1,58-65,11)$ ) were associated with higher mortality. Respiratory variables start to diverge significantly between survivors and non-survivors after the 96 to 120 hours from mechanical ventilation initiation, particularly respiratory system compliance. In non survivors, mechanical power at 24 and 96 hs was higher regardless ventilatory mode.

Conclusions: in patients admitted for SARS-CoV-2 pneumonia and requiring mechanical ventilation, non survivors have different respiratory system mechanics than survivors in the first 10 days of ICU admission. We propose a checkpoint at $96-120$ hs to assess patients improvement or worsening in order to consider escalating to extracorporeal therapies.

"TAKE HOME MESSAGE": assessing respiratory mechanics in the first 96-120 hs from ICU admission could predict the outcome of Covid-19 patients under mechanical ventilation.

\section{Introduction}

The clinical spectrum of SARS-CoV-2 infection (COVID-19) ranges from asymptomatic or paucisymptomatic cases to severe disease. The latter is usually characterized by severe community-acquired pneumonia with acute respiratory failure, acute respiratory distress syndrome (ARDS), septic shock and multiorgan failure. Current data suggest that $5-20 \%$ of COVID-19 patients develop critical illness $(1,2,3$, 4).

Controversy exists about the pathophysiology and lung mechanics of COVID-19 associated ARDS, because some report severe hypoxemia with preserved respiratory system mechanics, contrasting with "classic" ARDS $(5,6)$. 
A detailed analysis of the characteristics and time course of lung mechanics of patients requiring invasive mechanical ventilation (IMV) for COVID-19-associated ARDS and its association with outcome may guide the choice of ventilatory strategies. We compared IMV parameters in survivors and nonsurvivors of Covid-19-related ARDS.

\section{Material And Methods}

Our main objective was to compare respiratory system mechanics and gas exchange during the first ten days of IMV between ICU survivors and non-survivors. Secondary objectives were the association of clinical and biochemical characteristics with survival.

We performed a retrospective single-center observational study. Adult patients admitted to our 46-bed Department of Critical Care at Hospital Clínico San Carlos from March 5 to April 30, 2020 with respiratory failure due to RT-PCR-confirmed SARS-CoV-2 and discharged at the time of study were enrolled. For the study of lung mechanics and gas exchange, only data recorded within the first 10 days of ICU admission were collected (flow chart 1).

Patients were cared for by the usual ICU staff. Due to shortages of ICU ventilators, some patients were ventilated with anesthesia machines.

The Institutional Review Board approved the study and waived the need for informed consent (CEIC 21/170-E).

\section{Clinical and biochemical data:}

All variables were collected retrospectively from the electronic ICU information system $\left(\right.$ ICCA $^{\mathrm{TM}} \vee \mathrm{H} .02 .01$, Philips, The Netherlands). Patient data retrieved were age, sex, ethnicity, race, body mass index (BMI), Apache II score, days from onset of symptoms to ICU admission, ICU length of stay (LOS). Previous history of hypothyroidism, asthma, COPD, ACE inhibitor and SARS-CoV-2 drug therapy, renal dysfunction and use of renal replacement therapy, as well as extracorporeal membrane oxygenation and ICU mortality were recorded.

ICU admission and daily, hemoglobin, plasma creatinine and urea, lactate and arterial blood gases were registered. The following IMV parameters were recorded every hour: minute ventilation, breath rate, tidal volume, positive end-expiratory pressure (PEEP), peak pressure, driving pressure and respiratory system compliance. Mechanical power, its derived ratios and ventilator ratio were calculated as previously published (7-10). We studied volume control and pressure control recordings separately for each time point separately.

\section{Statistical analysis:}

All data were tested for normal distribution with the Kolmogorov-Smirnov test and are presented as mean \pm standard deviation or median with 25 th percentile and 75 th percentile, as appropriate. 
Proportions were compared using $\chi 2$ or Fisher exact tests. For dichotomic variables, T Student test and Mann-Whitney U test were used. Pearson or Spearman correlations were performed for continuous variables. Multivariate logistic analysis was performed using the statistically significant variables of the univariate comparisons between survivors and non survivors. Statistical significance was considered to be at two- sided $p<0.05$. All analyses were performed with SPPS v.25 (IBM Inc., USA).

\section{Results}

154 RT-PCR-confirmed Covid-19 patients were admitted during the study period, of whom 14 remained in the ICU at the time of analysis and were excluded.

Admission and baselines characteristics of survivors and non-survivors are listed in Table 1. All patients required mechanical ventilation and the global mortality was $38.6 \%$. Significant differences between survivors and non survivors were observed in Apache II score, age, prior angiotensin-converting-enzyme (ACE) inhibitors or angiotensin-receptor blockers (ARBs) therapy, need for vasopressors, use of extracorporeal membrane oxygenation (ECMO) and renal dysfunction. 
Table 1

Demographics and baseline characteristics

\begin{tabular}{|c|c|c|c|}
\hline & Survivors, $\mathrm{n}=86$ & Non Survivors, N= 54 & p \\
\hline Age, median (SD) & $57(51-66)$ & $66(57,75-73)$ & $<0,001$ \\
\hline Male sex, n (\%) & $55(64)$ & $38(70,4)$ & 0,276 \\
\hline Hispanic/latino ethnicity, n (\%) & $23(26,7)$ & $17(31,5)$ & 0,338 \\
\hline Comorbidities & $11(12,8)$ & $7(13)$ & 0,585 \\
\hline • Hypothyroidism n (\%) & $25(29,1)$ & $25(46,3)$ & 0,03 \\
\hline - ACE inhibitors or ARBs, $n$ (\%) & $7(8,1)$ & $4(7,4)$ & 0,574 \\
\hline • Asthma, n (\%) & $9(10,5)$ & $6(11,1)$ & 0,557 \\
\hline \multicolumn{4}{|l|}{ • COPD, n (\%) } \\
\hline Median, interquartile range & $27,7(25,7-31,2)$ & $27,55(25,9-29,4)$ & 0,556 \\
\hline BMI, & $14(9-19)$ & $20(15,5-26,5)$ & $<0,001$ \\
\hline Apache II, & $1(0-5)$ & $1,5(0-5,25)$ & 0,812 \\
\hline Admission to ICU, days & $10(6,75-12,25)$ & $8(7-12)$ & 0,516 \\
\hline Onset of symptoms, days & $14(8-24,5)$ & $16,5(8,75-24,25)$ & 0,988 \\
\hline \multicolumn{4}{|l|}{ ICU LOS } \\
\hline Plasma creatinine, mg/dl & $0,78(0,62-0,99)$ & $0,83(0,65-1,3)$ & 0,166 \\
\hline Plasma urea, mg/dl & $50,5(34,75-70,25)$ & $53(37,5-70,75)$ & 0,285 \\
\hline Drug therapy: & $66(76,7)$ & $40(74,1)$ & 0,435 \\
\hline • Lopinavir/ritonavir, n (\%) & $84(97,7)$ & $52(96,3)$ & 0,501 \\
\hline - Hydroxychloroquine, n (\%) & $33(38,4)$ & $18(33,3)$ & 0,338 \\
\hline • Interferon beta, n (\%) & $41(47,7)$ & $20(37)$ & 0,144 \\
\hline • Tocilizumab, n (\%) & $57(66,3)$ & $38(70,4)$ & 0,377 \\
\hline • Corticosteroids, n (\%) & $28(32,6)$ & $10(18,5)$ & 0,051 \\
\hline • Acetylcysteine, n (\%) & $77(89,5)$ & $52(96,3)$ & 0,129 \\
\hline • Ceftriaxone, n (\%) & $57(66,3)$ & $31(57,4)$ & 0,190 \\
\hline • Azithromycin, n (\%) & $57(66,3)$ & $45(83,3)$ & 0,020 \\
\hline • Noradrenalin, n (\%) & & & \\
\hline
\end{tabular}




\begin{tabular}{|llll|}
\hline & Survivors, $\mathbf{n = 8 6}$ & Non Survivors, N= 54 & p \\
\hline Outcomes: & $18(20,9)$ & $19(35,8)$ & $\mathbf{0 , 0 4 2}$ \\
- Oliguria, n (\%) & $4(4,7)$ & $13(24,5)$ & $\mathbf{0 , 0 0 1}$ \\
- Renal replacement therapy, n (\%) & $22(25,9)$ & $15(28,3)$ & 0,452 \\
- Prone position first 24 hs, n (\%) & 0 & $4(7,4)$ & $\mathbf{0 , 0 2 1}$ \\
- ECMO, n (\%) & & \\
\hline $\begin{array}{l}\text { ACE angiotensin-converting-enzyme, ARBs angiotensin-receptor blockers; COPD: chronic obstructive } \\
\text { pulmonary disease; BMl: body mass index; LOS: length of stay; MRSA: Methicillin-resistant }\end{array}$ \\
\hline \begin{tabular}{l} 
Staphyloccocus aureus. \\
\hline
\end{tabular}
\end{tabular}

Multivariate analysis showed that age, previous use of ACEI/ARBs and need of renal replacement therapies were associated with higher mortality (Table 2).

Table 2

Multivariate analysis for mortality

\begin{tabular}{|lll|}
\hline Variable & Odds ratio & p value \\
\hline Age & $1,092(1,014-1,176)$ & $0,021^{\star}$ \\
\hline APACHE II & $1,099(0,99-1,22)$ & 0,073 \\
\hline ACE inhibitors & $4,612(1,19-17,84)$ & $0,027^{\star}$ \\
\hline Oliguria & $0,253(0,05-1,2)$ & 0,084 \\
\hline RRT & $10,15(1,58-65,11)$ & $0,015^{\star}$ \\
\hline Noradrenaline & $1,3(0,33-5,07)$ & 0,7 \\
\hline ECMO & - & 0,99 \\
\hline
\end{tabular}

\section{Invasive Mechanical ventilation parameters during the first 10 days:}

We collected a total of 19,545 recordings and excluded 8407 not associated with pressure or volume controlled ventilator modes, leaving 11,138 recordings for analysis (figure 1).

In the first 5 days pressure control (PC) was the most frequently used ventilation mode, followed by volume control. Beyond this time point, patients were increasingly ventilated in pressure support (PS) mode (figure 2). There was no difference in the use of prone positioning in the first $24 \mathrm{hs}$ of admission.

A significant difference between survivors and non-survivors were observed for $\mathrm{PaO}_{2} / \mathrm{FiO}_{2}$ ratio (Figure 3.b) and ventilatory ratio (Figure 3.a.). Lung mechanics were similar over the first 96-120 hours but 
started to show significant differences beyond these time points. Significantly higher levels of PEEP were used in survivors from the start of mechanical ventilation (figure 4).

\section{Characteristics at 1, 24 and 96 hours of invasive mechanical ventilation (figure 3 and 4 and table E1)}

In the first hour of IMV, survivors had a significantly lower plasma lactate levels, whereas all other parameters were similar.

At 24 hours of IMV, results are different according to ventilation modes. In VC mode, non-survivors had a significantly lower $\mathrm{PaO}_{2} / \mathrm{FiO}_{2}$ ratio and higher ventilator ratio than survivors. However, driving pressure and respiratory system compliance were not different. Mechanical power and its normalized ratios (for IBW and Crs) were higher in non-survivors, who were ventilated with lower PEEP values, higher respiratory rates and higher tidal volumes. In PC mode, gas exchange variables were also different. Respiratory system compliance was lower in non-survivors. Mechanical power was higher in non-survivors who were ventilated with higher driving pressure and respiratory rates.

At 96 hours of IMV, we found that non-survivors ventilated in VC or PC mode, had significantly higher hemoglobin and lactate levels and higher ventilatory ratio. Mechanical power was higher in non survivors, regardless off ventilatory mode. $\mathrm{PaO}_{2} / \mathrm{FiO}_{2}$ ratio was not different in $\mathrm{VC}$ mode, but lower in PC. Nonsurvivors in VC mode were also ventilated with higher respiratory rates and driving pressures but lower PEEP levels and their respiratory system compliance was lower. In PC mode, tidal volume, PEEP and driving pressure were not different but minute ventilation and respiratory rates were higher.

\section{Discussion}

To the best of our knowledge, this is the first observational study describing the course of mechanical lung parameters of critically ill Covid-19 patients during IMV and their association with mortality, using a high-resolution analysis based on hourly recordings.

Earlier studies report mortality rates in mechanically ventilated Covid-19 patients as high as $60 \%(11-13)$. Mortality in our cohort was similar to more recent non-Covid-19 ARDS series (14), and characterized by non-survivors being predominantly male, older and with higher mean APACHE II score. Interestingly, body mass index in our series was not associated with a higher mortality, although height and weight are only estimated in our patients and bias cannot be excluded.

ACEI/ARBs treatment was associated with increased mortality, a finding in sharp contrast with the results of other studies $(15,16)$. However, this association is no longer significant when adjusting for age. We found that elderly patients were more frequently receiving ACEI/ARBs treatment before admission (see Figures E1 and E2 in the online data supplement).

Renal function at admission was similar in both groups, but patients developing oliguria and requiring RRT had a significantly higher risk of dying in the ICU. Although, SARS-Cov-2 may cause direct kidneys 
injury (17) IMV may contribute indirectly by influencing systemic hemodynamics. We found that controlled IMV on day 6 (144 hs) was associated with renal failure, an association previously reported by others (18) on day 8 of ICU admission.

Serum lactate dehydrogenase (LDH) increased in the first 24 hours of IMV and remained elevated during the first 10 days. Although LDH is associated with clinical deterioration in viral and Pneumocystis jirovecii pneumonia, it has also been related to ventilator induced injury (19). We actually found a negative correlation between LDH increase and dynamic compliance in survivors at all time points. This correlation was positive in non survivors, although not significant. Correlations of LDH serum concentrations with oxygenation and ventilation variables were significant (Table 3). We hypothesize that LDH elevation reflects increasing lung inflammation rather than VILI. We did not measure LDH isoenzymes, particularly type 3 , which were related to acute lung injury in previous studies $(20,21)$.

Table 3

Correlations between LDH and dynamic compliance, $\mathrm{PaO} 2 / \mathrm{FiO} 2$ and ventilator ratio.

\begin{tabular}{|c|c|c|c|c|c|c|}
\hline \multicolumn{2}{|c|}{ Hours of IMV } & \multirow[t]{2}{*}{ Cdyn } & \multirow[t]{2}{*}{$\mathrm{pO}_{2} / \mathrm{FiO}_{2}$} & \multirow[t]{2}{*}{ Ventilator ratio } & \multicolumn{2}{|l|}{ MP } \\
\hline & & & & & VC & PC \\
\hline \multirow[t]{2}{*}{24} & Survivors & $-0,197 *$ & $-0,190 *$ & $0,206^{*}$ & 0,022 & $0,240 *$ \\
\hline & Non-Survivors & 0,041 & $0,171^{*}$ & $0,271^{*}$ & $0,161^{*}$ & $0,335^{\star}$ \\
\hline \multirow[t]{2}{*}{96} & Survivors & $-0,366^{*}$ & $-0,308^{*}$ & $-0,086^{*}$ & 0,058 & 0,072 \\
\hline & Non-Survivors & $0,172^{\star}$ & $0,095^{\star}$ & $0,095^{\star}$ & $0,758^{\star}$ & $0,266^{*}$ \\
\hline \multirow[t]{2}{*}{$>144$} & Survivors & $-0,466^{*}$ & $-0,181^{*}$ & $-0,234^{\star}$ & $-0,105^{\star}$ & $-0,283^{*}$ \\
\hline & Non-Survivors & 0,017 & $-0,52^{\star}$ & $0,237 *$ & $0,349 *$ & $0,173^{*}$ \\
\hline
\end{tabular}

Respiratory variables start to diverge significantly between survivors and non-survivors during the 96 to 120 hours time interval (figures 2 and 3 and table E1). IMV variables and blood gases showed significant differences when IMV is switched from controlled to assisted modes (figure 3 ), and this seems to be associated with a higher mechanical power and tidal volumes applied in non-survivors, as well as a significantly higher respiratory rate and driving pressure at both time points. In all patients we titrated PEEP using a dynamic compliance-guided protocol. Because non-survivors had a lower recruitability, they were ventilated with lower PEEP values.

The significant association of a higher mechanical power and mortality merits further study as a potentially modifiable factor of IMV settings in Covid-19-associated ARDS. Tidal volumes at 96 hours were not different and VT/IBW remained always below $8 \mathrm{ml} / \mathrm{kg}$ (22) and may not be as relevant as they are in "classic" ARDS $(5,6)$. However, respiratory rate was clearly higher in non-survivors. Interestingly, we found that respiratory mechanics in VC mode were also significantly different in non-survivors. Therefore, considering the MP equation (8), in VC, the only modifiable variable is respiratory rate. Accordingly, PEEP was titrated using a dynamic compliance-guided protocol and TV/IBW was within accepted limits, 
although lower VT of $6 \mathrm{ml} / \mathrm{kg}$ could have been set (22). Respiratory system compliance, a surrogate of elastance, was lower during VC starting with ICU admission and can therefore not be attributed to mechanical ventilation settings, as mentioned above. We, therefore, consider that the choice of ventilation mode was rather related to attempts to optimize gas exchange and minute ventilation in patients with more severe disease, although higher RRs and driving pressures at 24 hs might have favoured the development of VILI in our patients. The consequence of these ventilator settings is the rise of driving pressures and the decrease of respiratory system compliance at 96 hs. Cressoni et al observed that even a short (less than 24 hour) course of high-energy ventilation induces VILI [23), a finding that correlates with our results.

Finally, 96-120 hours parameters may be used as a "checkpoint" to assess whether a patient it is improving or deteriorating and consider intensifying protective ventilation with extracorporeal support techniques. The Extracorporeal Life Support Organization Covid-19 guidelines contraindicate extracorporeal membrane oxygenation (ECMO) for patients mechanically ventilated for more than 10 days (24) and in most centers longer than 7 days. Recently published studies about the use of ECMO in Covid-19 patients report a median of 4 days between intubation and ECMO initiation (25-27). Our results suggest that less restrictive time window may be preferable. Specifically, worsening respiratory mechanics and not oxygenation should be considered to be an early indication of ECMO, because they occur earlier and prevention of VILI seems to be the most relevant objective in Covid-19 patients.

We acknowledge limitations of our single-center study. ICU ventilator shortage required the use of anaesthesia machine ventilators. This may have resulted in differences in ventilator settings and patient care in general not captured by our data collection and thus influenced our results. Our analyses also did not include other factors associated with different ventilator modes, like the characteristics of administration of sedatives and neuromuscular blockers. Due to the retrospective nature of our study, assessment of regional lung perfusion or shunt fraction, which would help explain the differences in oxygenation and ventilation variables, were not available.

\section{Conclusions}

we describe the clinical course over the first 10 days of invasive mechanical ventilation in Covid-19 patients and the variables associated with mortality. Respiratory rates might be a modifiable cause for VILI in these patients. Future studies are needed to evaluate whether modification of ventilation strategies or the use extracorporeal supportive interventions, particularly in the first 5 days from admission in the ICU, have an impact on prognosis.

\section{Declarations}

- FUNDING: not applicable.

- CONSENT FOR PUBLICATION: all authors and the hospital service gave their consent for publication.

- AVAILABILITY OF DATA AND MATERIAL: Full acces of complementary data. 
- COMPETING INTERESTS: not applicable.

- DISCLOSURE: all the authors declare no conflicts of interest.

- AUTHOR'S CONTRIBUTION: TFG, ANR and MSG designed the study. TFF, ANR and JL extracted and analyzed the data. TFF, JL, MCR, VYZ and SDM drafted the article. MSG revised the article and supervised the project. All authors revised the manuscript.

- ETHICS APPROVAL AND CONSENT TO PARTICIPATE: CEIC 21/170-E.

- ACKNOWLEDGMENTS: the authors thank Dr. Paloma González Arenas for her suggestions and for revising the article.

\section{References}

1. Zhu N, Zhang D, Wang W, Li X, Yang B, Song J, Zhao X, Huang B, Shi W, Lu R, Niu P, Zhan F, Ma X, Wang D, Xu W, Wu G, Gao GF, Tan W; China Novel Coronavirus Investigating and Research Team. A Novel Coronavirus from Patients with Pneumonia in China, 2019. N Engl J Med. 2020 Feb 20; 382 (8): 727-733. doi: 10.1056/NEJMoa2001017. Epub 2020 Jan 24.

2. WHO (2020) WHO Director-General's opening remarks at the media briefing on COVID-19. https://www.who.int/dg/speeches/detail/ who-director-general-s-opening-remarks-at-themediabriefing-on-covid-19--11-march-2020. Accessed 30 Mar 2020.

3. Dawei Wang, Bo Hu, Chang Hu, Fangfang Zhu, Xing L, Jing Zhang, Binbin Wang, Hui Xiang, Zhenshun Cheng, Yong Xiong, Yan Zhao, Yirong Li, Xinghuan Wang, Zhiyong Peng. Clinical Characteristics of 138 Hospitalized Patients With 2019 Novel Coronavirus-Infected Pneumonia in Wuhan, China. JAMA 2020 Feb 7; 323 (11): 1061-1069. doi: 10.1001/jama.2020.1585. Erratum in: JAMA. 2021 Mar 16;325(11):1113.

4. Grasselli G, Pesenti A, Cecconi M. Critical care utilization for the COVID-19 outbreak in Lombardy, Italy: early experience and forecast during an emergency response. JAMA. $2020 \mathrm{Apr}$ 28;323(16):1545-1546. doi: 10.1001/jama.2020.4031.

5. Gattinoni L, Coppola S, Cressoni M, Busana M, Rossi S, Chiumello D. Covid-19 does not lead to a "typical" acute respiratory distress syndrome. Am J Respir Crit Care Med. 2020; 201 (10): 12991300. doi: 10.1164/rccm.202003-0817LE.

6. Gattinoni L, Chiumello D, Caironi P, Busana M, Romitti F, Brazzi L, Camporota L. COVID-19 pneumonia: different respiratory treatments for different phenotypes? Intensive Care Med. 2020 Jun; 46(6): 1099-1102. doi: 10.1007/s00134-020-06033-2. Epub 2020 Apr 14.

7. Sinha P, Fauvel NJ, Singh S, Soni N. Ventilatory ratio: a simple bedside measure of ventilation. $\mathrm{Br} J$ Anaesth. 2009; 102 (5): 692-697. doi: 10.1093/bja/aep054. Epub 2009 Apr 3.

8. Gattinoni L, Tonetti T, Cressoni M, Cadringher P, Herrmann P, Moerer O, Protti A, Gotti M, Chiurazzi C, Carlesso $E$, Chiumello D, Quintel M. Ventilator-related causes of lung injury: the mechanical power. Intensive Care Med. 2016; 42 (10): 1567-1575. doi: 10.1007/s00134-016-4505-2. Epub 2016 Sep 12. 
9. Becher, T., van der Staay, M., Schädler, Frerichs I, Weiler N. Calculation of mechanical power for pressure-controlled ventilation. Intensive Care Med. 2019 Sep; 45(9), 1321-1323. doi:

10.1007/s00134-019-05636-8. Epub 2019 May 17.

10. Chiumello D, Gotti M, Guanziroli M, Formenti P, Umbrello M, Pasticci I, Mistraletti G, Busana M. Bedside calculation of mechanical power during volume- and pressure-controlled mechanical ventilation. Crit Care. 2020 Jul 11;24(1):417. doi: 10.1186/s13054-020-03116-w.

11. Wu C, Chen X, Cai Y, Xia J, Zhou X, Xu S, Huang H, Zhang L, Zhou X, Du C, Zhang Y, Song J, Wang S, Chao Y, Yang Z, Xu J, Zhou X, Chen D, Xiong W, Xu L, Zhou F, Jiang J, Bai C, Zheng J, Song Y. Risk Factors Associated With Acute Respiratory Distress Syndrome and Death in Patients With Coronavirus Disease 2019 Pneumonia in Wuhan, China. JAMA Intern Med. 2020 Jul 1;180(7):934943. doi: 10.1001/jamainternmed.2020.0994. Erratum in: JAMA Intern Med. 2020 Jul 1;180(7):1031.

12. Zhou F, Yu T, Du R, Fan G, Liu Y, Liu Z, Xiang J, Wang Y, Song B, Gu X, Guan L, Wei Y, Li H, Wu X, Xu J, Tu S, Zhang Y, Chen $\mathrm{H}, \mathrm{Cao} B$. Clinical course and risk factors for mortality of adult inpatients with COVID-19 in Wuhan, China: a retrospective cohort study. Lancet. 2020 Mar 28;395(10229):10541062. doi: 10.1016/S0140-6736(20)30566-3. Epub 2020 Mar 11. Erratum in: Lancet. 2020 Mar 28;395(10229):1038. Erratum in: Lancet. 2020 Mar 28;395(10229):1038.

13. Auld SC, Caridi-Scheible M, Blum JM, Robichaux C, Kraft C, Jacob JT, Jabaley CS, Carpenter D, Kaplow R, Hernandez-Romieu AC, Adelman MW, Martin GS, Coopersmith CM, Murphy DJ; Emory COVID-19 Quality and Clinical Research Collaborative. ICU and Ventilator Mortality Among Critically III Adults With Coronavirus Disease 2019. Crit Care Med. 2020 Sep;48(9): e799-e804. doi: 10.1097/CCM.0000000000004457.

14. Bellani G, Laffey JG, Pham T, Fan E, Brochard L, Esteban A, Gattinoni L, van Haren F, Larsson A, McAuley DF, Ranieri M, Rubenfeld G, Thompson BT, Wrigge H, Slutsky AS, Pesenti A; LUNG SAFE Investigators; ESICM Trials Group. Epidemiology, Patterns of Care, and Mortality for Patients With Acute Respiratory Distress Syndrome in Intensive Care Units in 50 Countries. JAMA. 2016 Feb 23;315(8):788-800. doi: 10.1001/jama.2016.0291. Erratum in: JAMA. 2016 Jul 19;316(3):350. Erratum in: JAMA. 2016 Jul 19;316(3):350.

15. Rico-Mesa JS, White A, Anderson AS. Outcomes in Patients with COVID-19 Infection Taking ACEI/ARB. Curr Cardiol Rep. 2020 Apr 14;22(5):31. doi: 10.1007/s11886-020-01291-4.

16. Mancia G, Rea F, Ludergnani M, Apolone G, Corrao G. Renin-angiotensin-aldosterone system blockers and the risk of Covid-19. N Engl J Med. 2020 Jun 18;382(25):2431-2440. doi: 10.1056/NEJMoa2006923. Epub 2020 May 1.

17. Su H, Yang M, Wan C, Yi LX, Tang F, Zhu HY, Yi F, Yang HC, Fogo AB, Nie X, Zhang C. Renal histopathological analysis of 26 postmortem findings of patients with COVID-19 in China. Kidney Int. 2020 Jul;98(1):219-227. doi: 10.1016/j.kint.2020.04.003. Epub 2020 Apr 9.

18. Hirsch JS, Ng JH, Ross DW, Sharma P, Shah HH, Barnett RL, Hazzan AD, Fishbane S, Jhaveri KD; Northwell COVID-19 Research Consortium; Northwell Nephrology COVID-19 Research Consortium. 
Acute kidney injury in patients hospitalized with COVID-19. Kidney Int. 2020 Jul;98(1):209-218. doi: 10.1016/j.kint.2020.05.006. Epub 2020 May 16.

19. Lim SC, Kim YI. The role of the lactate dehydrogenase and the effect of prone position during ventilator-induced lung injury. J Korean Med Sci. 2004 Apr;19(2):223-8. doi: 10.3346/jkms.2004.19.2.223.

20. Hagadorn JE, Bloor CM, Yang MS. Elevated plasma activity of lactate dehydrogenase isoenzyme-3 (LDH 3) in experimentally induced immunologic lung injury. Am J Pathol. 1971 Sep;64(3):575-81.

21. Drent M, Cobben NA, Henderson RF, Wouters EF, van Dieijen-Visser M. Usefulness of lactate dehydrogenase and its isoenzymes as indicators of lung damage or inflammation. Eur Respir J. 1996 Aug;9(8):1736-42. doi: 10.1183/09031936.96.09081736.

22. Alhazzani W, Møller MH, Arabi YM, Loeb M, Gong MN, Fan E, Oczkowski S, Levy MM, Derde L, Dzierba A, Du B, Aboodi M, Wunsch H, Cecconi M, Koh Y, Chertow DS, Maitland K, Alshamsi F, BelleyCote E, Greco M, Laundy M, Morgan JS, Kesecioglu J, McGeer A, Mermel L, Mammen MJ, Alexander PE, Arrington A, Centofanti JE, Citerio G, Baw B, Memish ZA, Hammond N, Hayden FG, Evans L, Rhodes A. Surviving Sepsis Campaign: Guidelines on the Management of Critically III Adults with Coronavirus Disease 2019 (COVID-19). Crit Care Med. 2020 Jun;48(6): e440-e469. doi: 10.1097/CCM.0000000000004363.

23. Cressoni M, Chiurazzi C, Gotti M, et al. Lung inhomogeneities and time course of ventilator-induced mechanical injuries. Anesthesiology 2015; 123: 618-27. doi: 10.1097/ALN.0000000000000727.

24. Shekar, K., Badulak, J., Peek, G., Boeken, U., Dalton, H. J., Arora, L., Zakhary, B., Ramanathan, K., Starr, J., Akkanti, B., Antonini, M. V., Ogino, M. T., Raman, L., \& ELSO Guideline Working Group* (2020). Extracorporeal Life Support Organization COVID-19 Interim Guidelines. ASAIO journal (American Society for Artificial Internal Organs: 1992), 10.1097/MAT.0000000000001193. Advance online publication. https://doi.org/10.1097/MAT.0000000000001193

25. Mustafa AK, Alexander PJ, Joshi DJ, Tabachnick DR, Cross CA, Pappas PS, Tatooles AJ. Extracorporeal Membrane Oxygenation for Patients With COVID-19 in Severe Respiratory Failure. JAMA Surg. 2020 Aug 11;155(10): 990-2. doi: 10.1001/jamasurg.2020.3950.

26. Barbaro RP, MacLaren G, Boonstra PS, Iwashyna TJ, Slutsky AS, Fan E, Bartlett RH, Tonna JE, Hyslop R, Fanning JJ, Rycus PT, Hyer SJ, Anders MM, Agerstrand CL, Hryniewicz K, Diaz R, Lorusso R, Combes A, Brodie D; Extracorporeal Life Support Organization. Extracorporeal membrane oxygenation support in COVID-19: an international cohort study of the Extracorporeal Life Support Organization registry. Lancet. 2020 Oct 10;396(10257):1071-1078. doi: 10.1016/S01406736(20)32008-0. Epub 2020 Sep 25. Erratum in: Lancet. 2020 Oct 10;396(10257):1070.

27. Kon ZN, Smith DE, Chang SH, Goldenberg RM, Angel LF, Carillo JA, Geraci TC, Cerfolio RJ, Montgomery RA, Moazami N, Galloway AC. Extracorporeal Membrane Oxygenation Support in Severe COVID-19. Ann Thorac Surg. 2021 Feb;111(2):537-543. doi: 10.1016/j.athoracsur.2020.07.002. Epub 2020 Jul 17. 
Figures

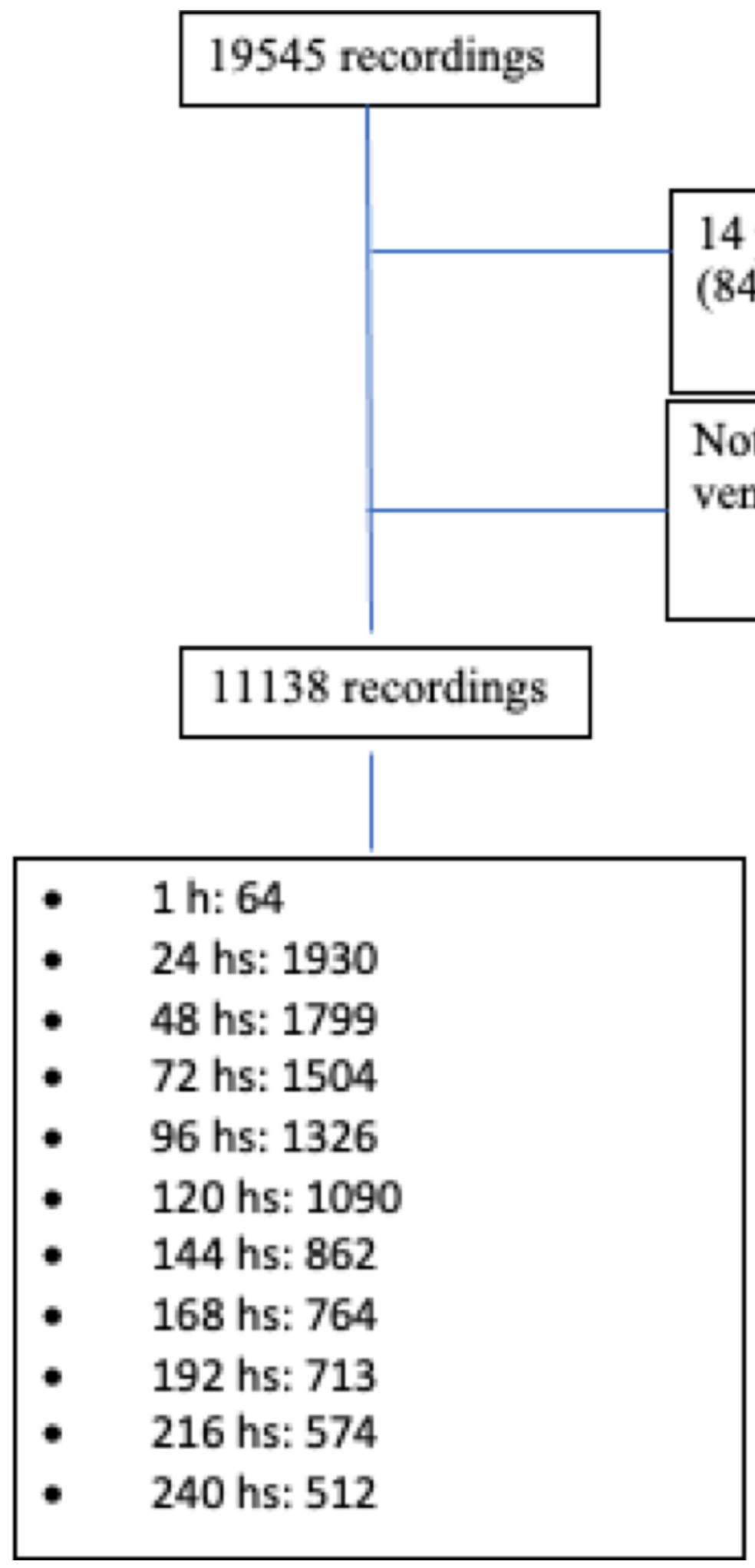

Figure 1

Flow chart 


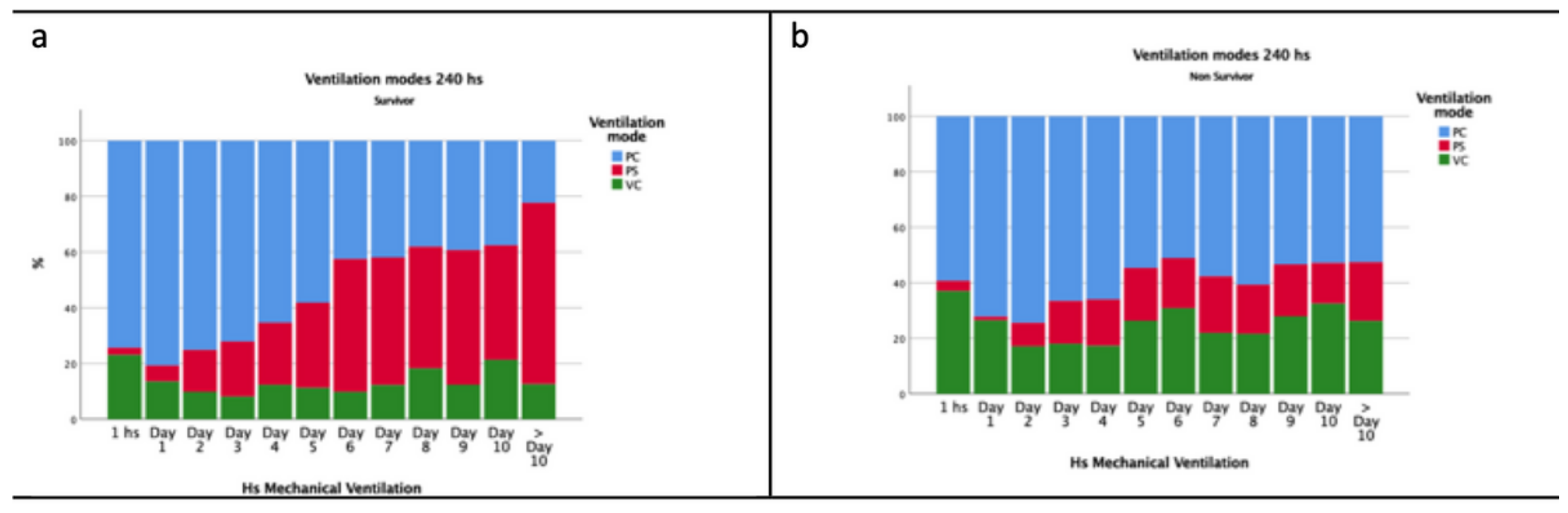

Figure 2

percentage prevalence of ventilation modes in survivors (a.) and non-survivors (b.) over the first 10 days of mechanical ventilation.

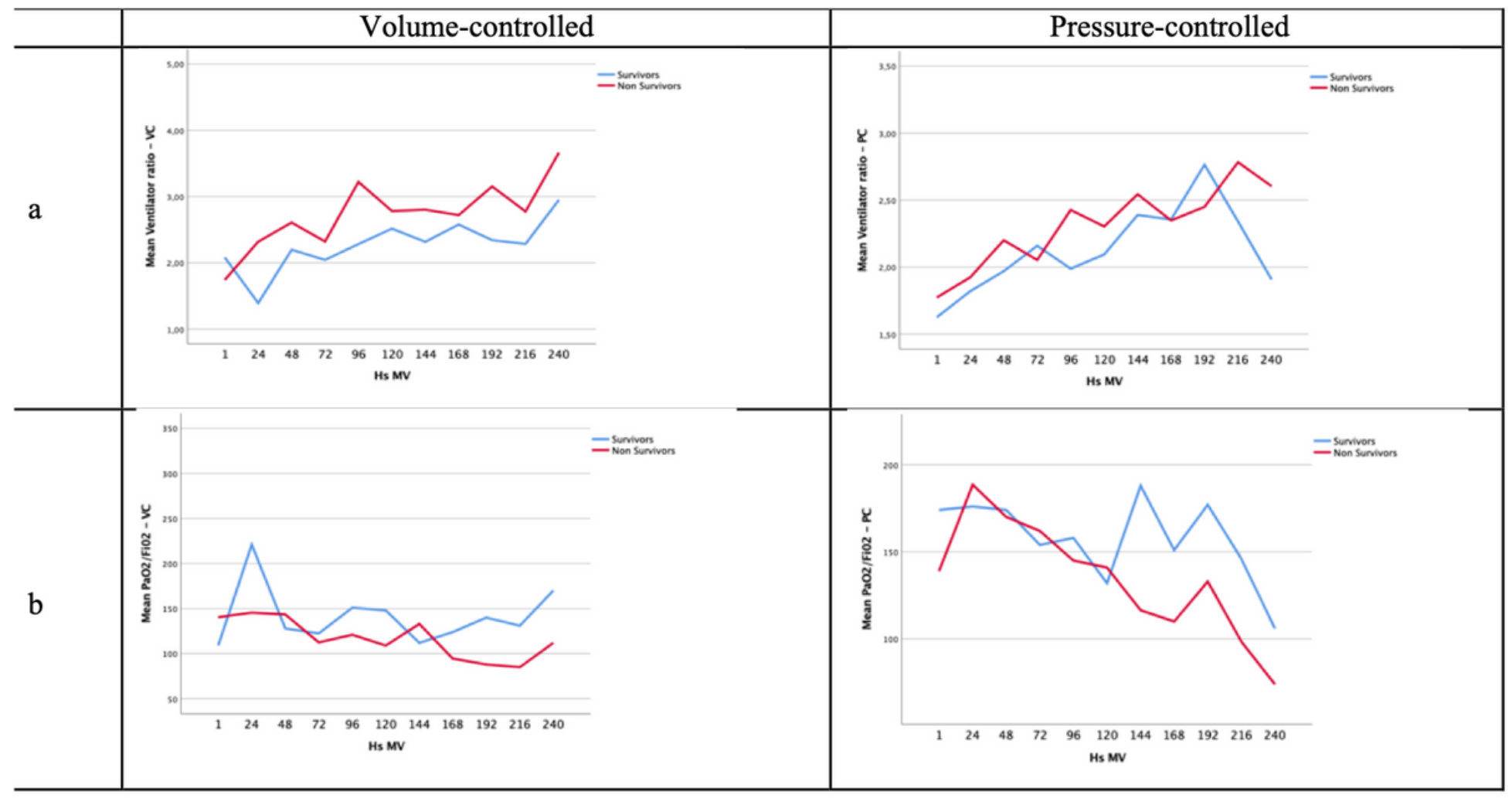

\section{Figure 3}

Median ventilatory ratio (a.) and $\mathrm{PaO2} / \mathrm{FiO2}$ ratio (b.). Hours of mechanical ventilation plotted on $\mathrm{x}$-axis over the first 10 days in survivors and non-survivors and in volume and pressure-controlled modes. 


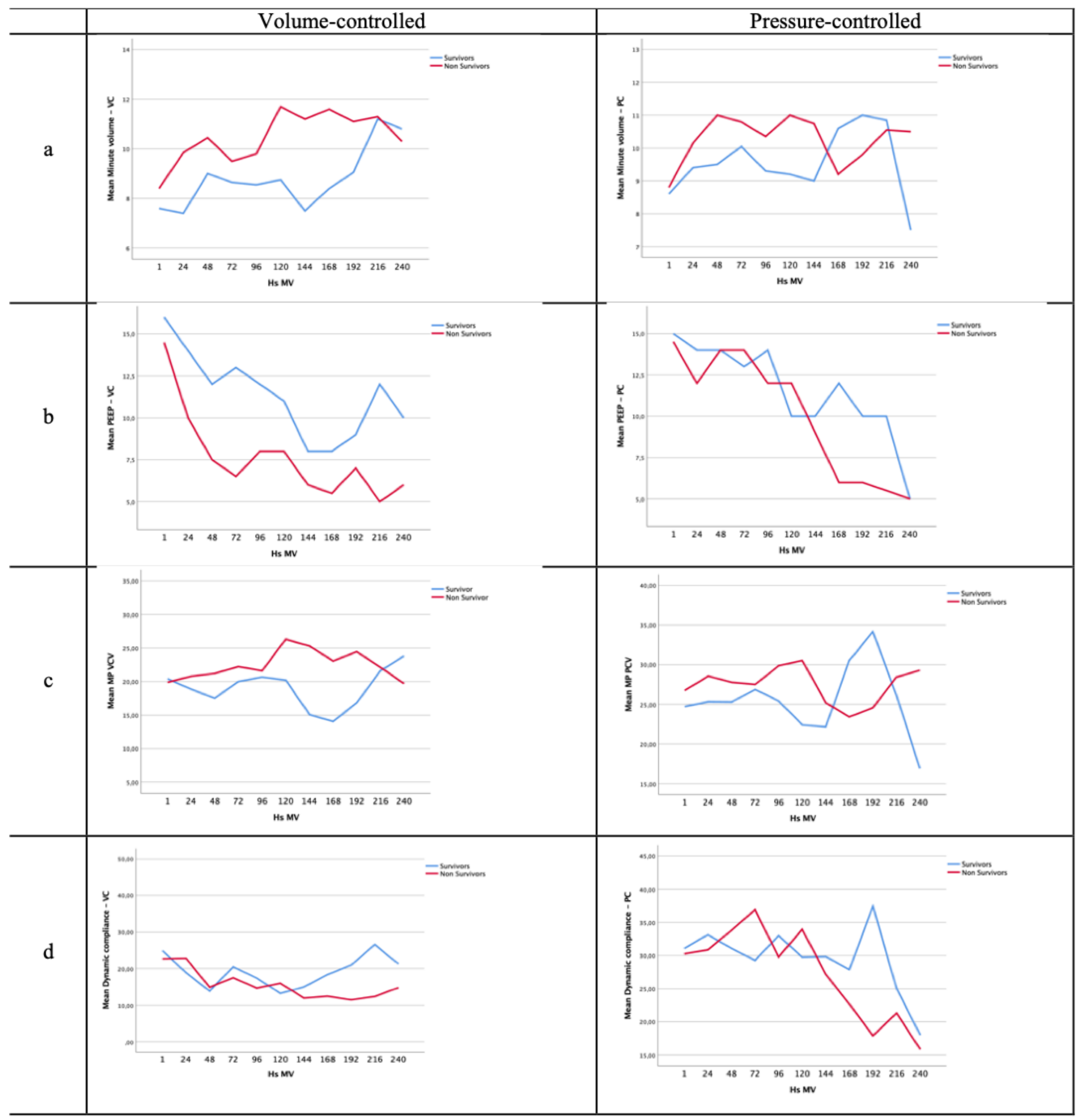

\section{Figure 4}

Mean minute volume (a.), PEEP (b.), mechanical power (c.) and dynamic compliance (d.). Hours of mechanical ventilation plotted on $x$-axis by hours of mechanical ventilation over the first 10 days in survivors and non-survivors in volume and pressure-controlled ventilation modes.

\section{Supplementary Files}


This is a list of supplementary files associated with this preprint. Click to download.

- OnlineSupplementalmaterial.docx 